\title{
WHAT KIND OF VIDEO GAMER ARE YOU?
}

Nadia Jiménez ${ }^{1}$, Sonia San-Martín ${ }^{2}$, Carmen Camarero ${ }^{3}$, Rebeca San Jose Cabezudo ${ }^{4}$

Department of Economics and Business Administration, Universidad de Burgos ${ }^{1,2}$

Department of Business Management and Marketing, Universidad de Valladolid ${ }^{3,4}$

Nadia Jiménez ${ }^{1}$

Facultad de Ciencias Económicas y Empresariales, C/ Parralillos, s/n, Universidad de Burgos

Email: nhjimenez@ubu.es

ORCID ID: 0000-0001-5771-2971

Sonia San-Martín ${ }^{1}$

Facultad de Ciencias Económicas y Empresariales, C/ Parralillos, s/n, Universidad de Burgos

Email: sanmargu@ubu.es

ORCID ID: 0000-0002-5030-9669

Carmen Camarero ${ }^{3}$

Facultad de Ciencias Económicas y Empresariales, Avda del Valle Esgueva 6,

Universidad de Valladolid

Email: carmen.camarero@uva.es

ORCID ID: 0000-0002-5252-4581

Rebeca San Jose Cabezudo ${ }^{4}$

Facultad de Ciencias Económicas y Empresariales, Universidad de Valladolid, Avda del Valle Esgueva 6, Universidad de Valladolid

Email: rebecasc@eco.uva.es

ORCID ID: 0000-0002-9161-6657

\section{Acknowledgment}

The authors would like to thank the support provided by the Ministry of Economy and Competitiveness (ECO2017-82107-R) and the European Regional Development Fund (ERDF) and Junta de Castilla y León (Spain) (VA112P17).

This is the accepted version of the manuscript: Jimenez, N., San-Martin, S., Camarero, C., \& San Jose Cabezudo, R. (2019). What kind of video gamer are you? Journal of Consumer Marketing, 36(1), 218-227. https://doi.org/10.1108/JCM-06-2017-2249 


\title{
WHAT KIND OF VIDEO GAMER ARE YOU?
}

\begin{abstract}
Purpose.- This paper attempts to understand the extent to which the effect of motivations on purchase intention varies for diverse segments of video gamers (depending on their personality).

Design/Methodology.- Information was collected from 511 Spanish video game consumers. Structural equation modeling, clustering, and multi-group analysis were then conducted to compare results between segments of gamers.

Findings.- Results show that hedonic, social and mainly addiction motivations lead to purchase intention of game-related products. Moreover, we identify a typology of gamer that gives rise to differences in motivations-purchase intention links: (1) Analysts include individuals who are essentially conscientious, prefer inventive or cognitive and simulation games and whose behavior is more influenced by hedonic and social motivations to play; (2) Socializers comprise individuals who are mainly extrovert and emotionally stable gamers and who prefer sports and strategy games. The motivations to play that affect their purchase intentions are mainly social; and (3) Sentinels include individuals that are unmindful and introvert, prefer inventive, cognitive, sports and simulation games, and whose social motivations drive their purchase intentions.

Originality.- There are 2,200 million video gamers around the world, although it is assumed that this vast market is not homogeneous, which has implications for consumer motivations and purchase intention. However, the currently available classifications that address this challenge are rather limited. In this sense, the present paper provides valuable insights into understanding how personality offers a useful variable to segment consumers in the video game industry and how it moderates the effect of motivations on purchase behavior.
\end{abstract}

\section{Keywords}

Typology, Video games, Personality, Motivations 


\section{Introduction}

Video games are products that generate an enormous volume of business worldwide. Indeed, there are 2,200 million gamers in the world, and the value of the global gaming market stands at over 119 billion euros (Newzoo, 2018; DEV, 2017).

Attempts to understand gamer behavior have thus far failed to attract many researchers and academicians, despite which this line of research can no doubt gain tremendous momentum thanks to the ongoing interest in game playing (Jeromin et al., 2016; Mukherjee and Lau-Gesk, 2016). Gaming ${ }^{[1]}$ has been analyzed in the literature from various perspectives, although these have tended to focus on the positive or negative aspects of video game use (Kuo et al., 2016; Jeromin et al., 2016) whilst existing typologies of gamers are based on age (Griffiths et al., 2004), time spent playing (Ip et al., 2008; Fu et al., 2017), playing performance (Drachen et al., 2009, Fu et al., 2017; Huo, 2012), frequency of playing (Manero et al., 2016; Fu et al., 2017), game genre preferences (Ip et al., 2008; Manero et al., 2016), personality traits and gaming disorders (Braun et al., 2016) or motivations (Tseng, 2011). Video games have been shown to provide gamers with a wide variety of benefits (Velez and Hanus, 2016), although we have not found any study that considers the phenomenon from a marketing standpoint that seeks to discern the effect of gamer motivations when purchasing game-related products and taking into account their personality. To the best of our knowledge, only one recent study explores gamers in terms of their personality, although it only focuses on one particular video game (World of Warcraft) (Bean et al., 2016) and does not include multi-group analysis per segment. Nevertheless, Mogre et al. (2017) stress the importance of furthering marketing knowledge in novel and popular industries, such as the video game industry.

This paper aims to fill this research gap by offering a causal model of relations between motivations and purchase intentions of video game-related products, a typology of video gamers and a multi-group analysis in order to compare segments. The main research 
question is thus formulated as follows: does the motivation effect on purchase intention vary for different segments of video gamers (depending on their personality)?

The contributions are: (1) The study of a fast-growing industry such as the video game industry, specifically addressing an understanding of the main groups of gamers so as to help firms segment their market, catering to gamers' personality. (2) This study offers empirical evidence on how the role that motivations play on purchase behavior varies depending on gamer personality, whereas most prior research into types of video gamer has been merely descriptive.

\section{Literature review}

\subsection{The effect of motivations on the purchase of game-related products}

Different people are attracted to games for a variety of reasons. These include enjoyment, socializing, collaborating, competing, seeking recognition, escaping from routine, and other reasons (Williams, 2016; Liu, 2017). Gamer behavior stems from certain motivational drivers (Huang and Hsieh, 2011). The Uses and Gratifications Theory and the Flow Theory are two of the most widely used approaches that examine the adoption of innovative and mainly entertaining products (such as video games) (Huang et al., 2017; Boyle et al., 2012; Williams et al., 2008; Liu, 2017; Mukherjee and Lau-Gesk, 2016; Csikszentmihalyi, 1975; Huang et al., 2017). The Uses and Gratifications Theory posits that individuals use games to meet specific needs, such as enjoying video game content in order to have fun (acquiring pleasurable experiences, i.e., process and/or entertainment gratifications) or that individuals use games to foster their social relationships in a gaming environment (acquiring social stimulation, i.e. social gratifications) (Huang and Hsieh, 2011). Following Williams et al. (2008) and Chen and Leung (2016), the Uses and Gratifications Theory represents a framework for discussing and measuring motivations for playing and can provide tools to better explore whether different subgroups of gamers are motivated differently, and whether motivations determine what they do. 
Li et al. (2015) and Wei and $\mathrm{Lu}$ (2014) point out that research into the Uses and Gratifications Theory identifies three types of gratifications related to game use (content gratifications, process gratifications, and social gratifications), which Huang et al. (2017) later refer to as the hedonic, utilitarian and social gratifications of gaming. However, some scholars suggest that hedonic and social motives are the crucial aspects to consider when analyzing consumer behavior regarding entertaining products - i.e. video games - (Chen and Wang, 2016; Wei and Lu, 2014). The Flow Theory suggests that for hedonic activities such as gaming there must be a balance between the inherent challenge and gamer ability to perform the activity. The gamer is thus more likely to experience flow and so to continue gaming (Liu, 2017). In this line, hedonic motivation refers to the extent to which playing video games is perceived as an entertainment motive (Li et al., 2015). Hedonic motivation involves a more process-based perspective for video games, using and representing them as a means to spend time gaining pleasure or stimulating gamers' minds with pleasurable tasks (Love and Irani, 2007; Huang and Hsieh, 2011; Huang et al., 2017). At the same time, those playing video games pursue a challenge and seek to achieve an in-game goal (Ryan and Deci, 2000; Yee, 2006; Huang et al., 2017).

Prior studies have found that consumers continue playing a video game with greater motivation if they perceive intense enjoyment (Colwell, 2007; Ha et al., 2007). Furthermore, hedonic motivation has been found to significantly influence consumers' intention to play video games (Davis et al., 2013; Wei and Lu, 2014; Huang et a., 2017). It seems reasonable to assume that if gamers derive enjoyment and fun from video games, then they may be willing to buy more video game-related products in order to entertain themselves and keep playing (Huang et a., 2017; Li et al., 2015). As video games are mainly hedonic products for entertainment (Chen and Wang, 2016; Huang et al., 2017), the current work thus considers that achieving pleasure, flow and perceived enjoyment (hedonic motivation) is a positive trigger of game-related product purchase. Hence,

H1. Hedonic motivation positively influences purchase intention regarding video gamerelated products.

In line with the Social Comparison Theory (Festinger, 1954), gamers might be motivated to seek feedback about their abilities in order to confirm a stable and accurate self-view. 
Video-game products thus involve competition and social motives to interact with other gamers, to self-improve or to gain recognition (Søraker, 2016). Likewise, the Uses and Gratifications Theory also postulates that social gratification reflects the extent to which a player's psychological sense of physically interacting and establishing a personal connection with others is driven by playing video games (Li et al., 2015; Williams et al., 2008). Through video games, gamers have found an excellent way of measuring their progress against their friends or other gamers, which may satisfy their social needs and desires (Huang et al., 2017; Zimmerman, 2009; Søraker, 2016). Previous research has also identified that social motivation is a key factor that makes users more engaged with playing video games (Wei and Lu, 2014; Cole and Griffiths, 2007). It is widely accepted in the literature that gamers spend more time and money on games for social motives (Hou, 2012; Huang and Hsieh, 2011; Li et al., 2015). Consequently, even when speaking about free video games, Søraker (2016, p. 114) highlights that "gamers will usually come to a point where it turns out that all the time invested still does not allow them to compete against those who spend money or that some game features are simply made unavailable to non-paying gamers." At this point, gamers might start purchasing game-related products with the purpose of keep playing, socializing and competing with or against others (Søraker, 2016). Therefore,

H2. Social motivation positively influences purchase intention regarding video gamerelated products.

Last but not least, addiction might represent an underlying driver of video game-related purchase behavior, which has been less researched in consumer literature than the two previously mentioned motivations (McBride and Derevensky, 2009; Mukherjee and LauGesk, 2016; Kuo et al., 2016). Neuroscientific research into rewards and dopamine neurotransmission suggests that brain circuits for gratification drive many human behaviors (Berridge, 2007). Søraker (2016) suggests that seeking rewards in the video game context might result in an urge to keep playing (i.e., addictive motives) rather than just enjoying a pleasurable experience. Addiction motivation might therefore be driving gamer behavior (Søraker, 2016). Gaming addiction is seen as a disorder that involves the continued use of video games, too much time spent gaming and difficulty in stopping gaming (van Rooij et al., 2012; McBride and Derevensky, 2009). In fact, numerous gamers seem susceptible to addiction (Chen and Leung, 2016; Liu and Chang, 2016). Lu 
and Wang (2008) state that addiction is a motivation to explain why gamers are loyal and stick to video games. These gamers explain that when consumers have addictive motives for gaming, they try to get the maximum value for their preferences, which can in fact prompt gamer purchasing with regard to video game-related products. As a result,

H3. Addiction motivation positively influences purchase intention regarding video gamerelated products.

Figure 1 shows the proposed hypotheses.

Figure 1. Proposed model

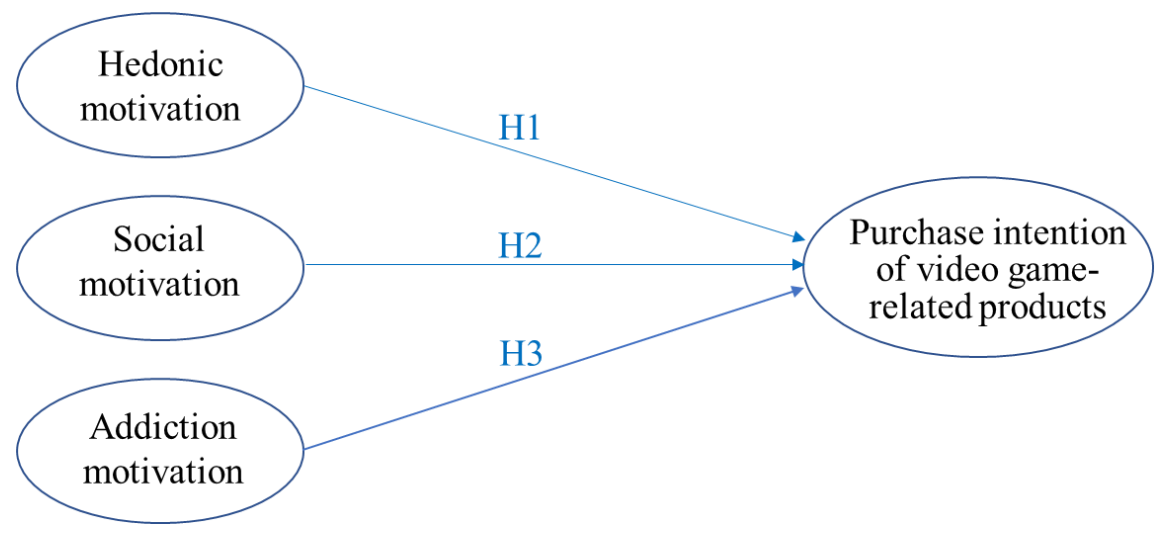

\subsection{Gamer segmentation according to personality}

It is well accepted and standard practice for firms to divide potential consumers into segments to enable them to target those most likely to buy their products. In fact, this is a widespread practice in the gaming industry (Drachen et al., 2012). The literature recognizes that in the gaming industry it is crucial to segment gamers so as to design customized strategies and increase player retention (Fu et al., 2017), promote loyalty (Sheu et al., 2009) and understand playing behavior patterns (Drachen et al., 2009). Fu et al. (2017) point out that segmentation is especially important in the gaming sector since gamers have a much higher withdrawal rate than customers in other industries. Moreover, Dracher et al. (2012) state that clustering analysis in the case of video gamers is of interest in academic research, especially for areas that focus on player experience, behavioral modeling and game development. A crucial step in consumer categorization is to select 
segmentation variables (Chen et al., 2016). Some previous research in gaming literature has identified certain segments of gamers based on their demographic characteristics (Griffiths et al., 2004), time spent playing, game-related purchases and favorite games (Ip et al., 2008; Hou, 2012; Manero et al., 2016; Fu et al., 2017), skills (Drachen et al., 2009; Fu et al., 2017), motivations (Tseng, 2011), personality traits and internet gaming disorders (Braun et al., 2016). Table 1 shows a literature review of video gamer segmentation and categorization, as well as recent pre-existing typologies.

Table 1. Review on players' segmentation

\begin{tabular}{|c|c|c|c|}
\hline Authors & Variables & Segmentation method/sample & Segments \\
\hline $\begin{array}{l}\text { Griffiths } \\
\text { et al. } \\
(2004)\end{array}$ & Age. & $\begin{array}{l}\text { A priori segmentation/ } \\
540 \text { online players. }\end{array}$ & Adults and adolescents. \\
\hline $\begin{array}{l}\text { Ip et al. } \\
\text { (2008) }\end{array}$ & $\begin{array}{l}\text { Time playing and purchases } \\
\text { related to games. }\end{array}$ & $\begin{array}{l}\text { A priori segmentation and descriptive } \\
\text { differences between groups/ } \\
713 \text { students. }\end{array}$ & $\begin{array}{l}\text { Non-gamers, infrequent } \\
\text { gamers, regular gamers and } \\
\text { frequent gamers. }\end{array}$ \\
\hline $\begin{array}{l}\text { Drachen } \\
\text { et al. } \\
(2009)\end{array}$ & $\begin{array}{l}\text { Causes of death, total } \\
\text { deaths, completion time } \\
\text { and help-on-demand }\end{array}$ & $\begin{array}{l}\text { A posteriori segmentation with self- } \\
\text { organizing map algorithm/ } \\
25240 \text { players. }\end{array}$ & Veterans, pacifists and runners. \\
\hline $\begin{array}{l}\text { Tseng } \\
(2011)\end{array}$ & $\begin{array}{c}\text { Motivations (need for } \\
\text { exploration and aggression) }\end{array}$ & $\begin{array}{l}\text { A posteriori segmentation with k- } \\
\text { means analysis/ } \\
228 \text { players }\end{array}$ & $\begin{array}{l}\text { Aggressive gamers, social } \\
\text { gamers and inactive gamers. }\end{array}$ \\
\hline $\begin{array}{l}\text { Hou } \\
(2012)\end{array}$ & $\begin{array}{l}\text { Degree of participation } \\
\text { regarding several } \\
\text { behavioral actions and } \\
\text { gaming tool used. }\end{array}$ & $\begin{array}{c}\text { A posteriori segmentation with k- } \\
\text { means analysis/ } \\
100 \text { players }\end{array}$ & $\begin{array}{c}\text { Hard-core gamers, high- } \\
\text { participation gamers and } \\
\text { ordinary-participation gamers. }\end{array}$ \\
\hline $\begin{array}{c}\text { Braun et } \\
\text { al. (2016) }\end{array}$ & $\begin{array}{c}\text { Personality traits and } \\
\text { internet gaming disorder. }\end{array}$ & $\begin{array}{l}\text { A priori segmentation and descriptive } \\
\text { differences between groups/ } \\
2891 \text { subjects }\end{array}$ & $\begin{array}{l}\text { Gaming addicts and non- } \\
\text { gamers in comparison to } \\
\text { regular gamers. }\end{array}$ \\
\hline $\begin{array}{l}\text { Manero et } \\
\text { al. (2016) }\end{array}$ & $\begin{array}{l}\text { Gaming frequency and } \\
\text { gaming preferences per } \\
\text { game genre. }\end{array}$ & $\begin{array}{c}\text { A posteriori segmentation with k- } \\
\text { means analysis/ } \\
754 \text { students }\end{array}$ & $\begin{array}{l}\text { Casual gamers, non-gamer, } \\
\text { hardcore, and well-rounded } \\
\text { gamers }\end{array}$ \\
\hline $\begin{array}{l}\text { Fu et al. } \\
(2017)\end{array}$ & $\begin{array}{c}\text { Playtime, level, guild status } \\
\text { and time, awards, } \\
\text { frequency, and friends. }\end{array}$ & $\begin{array}{c}\text { A posteriori segmentation with k- } \\
\text { means analysis/ } \\
12379 \text { players }\end{array}$ & $\begin{array}{l}\text { Leaders and aggressive gamers, } \\
\text { churners, explorers and } \\
\text { achievers }\end{array}$ \\
\hline
\end{tabular}

Two broad approaches to market segmentation can be delineated in previous literature (Sandy et al., 2013). The most common approach relies on segmenting by demographic variables (e.g. age, gender). In fact, gender based market segmentation is a commonly used technique in consumer marketing behavior (Polyzou et al., 2016; Faqih, 2016). The 
second approach (known as "psychographics") identifies market divisions in terms of psychological variables such as values, attitudes, and personality traits. In fact, earlier psychographic segmentation was heavily rooted in personality profiling. For certain behaviors (i.e., electronic purchases), demographics displayed greater predictive potential than psychographics, while for others, psychographics proved more useful (i.e., television shows) (Sandy et al., 2013; Culig and Rukavina, 2012; Krolo et al., 2016). In addition, Mount et al. (2005), Faqih (2016), Polyzou et al. (2016) posit that among psychographic variables, personality traits are especially useful to predict global consumer behavior. Following Huang and Hsieh, (2011, p. 582), the prevalent use of technological variables (i.e. playtime, leveling speed, deaths, awards or game genre) in gamer behavior research highlights the need to shift the focus toward non-technological aspects and encourages theoretical parsimony in gaming research.

A few studies have explored personality aspects as a way to better understand gamers. In the literature, certain authors manifest their concern about the relevance of personality aspects to understand gamer versus non-gamer behavior (Estallo, 1995; Teng, 2008; Abarbanel, 2013) whilst others agree that gamers' personality is projected into specific in-game behaviors, playing style and game genre preference (Zammitto, 2010; Hartmann and Klimmt, 2006; Braun et al., 2016; deGraft-Johnson et al., 2013; Worth and Book, 2014; Culig and Rukavina, 2012; Krolo et al., 2016). Following Bateman and Boon (2005), game design should reflect the desires and preferences of the audience, and consumer models, such as the Big Five Model, should be used as a tool to identify gamers' needs. In fact, a recent study (Braun et al., 2016) offers evidence that personality traits are useful for distinguishing non-gamers (rest of the population) from regular gamers and even from gaming addicts. Therefore, we aim to address the following research question: $R Q_{1}$. are there different types of gamers depending on their personality?

As for the theoretical framework for studying personality, the Trait Theory is the most influential school of thought in psychology (Chen and Chang, 1989). Mehrabian and Russell (1974) note that personality traits could influence how a person would react in a given environment. The Big Five Model is one of the most well-known and widely used personality models in psychology to measure those five personality traits (Costa and McCrae, 1985; Landers and Lounsbury, 2006; Lin, 2010; Ryan and Xenos, 2011; Saleem et al., 2011). Behaviors are indeed better understood when using a robust framework such 
as the Big Five (Costa and McCrae, 1985; Lin, 2010; Loveland et al., 2015). Sandy et al. (2013) group variables into blocks to examine the effect of personality variables -as a whole-, and not to examine the predictive effect of particular personality traits. As other authors have done (Roberts et al., 2007), Sandy et al. (2013) state that adding the Big Five helps to increase the explained variance when predicting behavior outcomes.

Following Costa and McCrae (1985), Lin (2010), Saleem et al. (2011) and deGraftJohnson et al. (2013), the Big Five personality traits reflect the degree to which consumers see themselves with regard to five dimensions. Conscientiousness assesses one's degree of organization, persistence, and motivation in goal-directed behavior. Neuroticism refers to an individual prone to psychological distress, excessive cravings or urges, and maladaptive coping responses. Extraversion comprises an individual's quantity and intensity of interpersonal interaction and activity level. Agreeableness assesses an individual's quality of interpersonal orientation along a continuum from compassion to antagonism in thoughts, feelings, and actions. Openness relates to an individual's proactive seeking and appreciation of experience for its own sake, toleration for, and exploration of the unfamiliar.

Some of these traits have scarcely been addressed in scientific studies in the context of video gamers (Manero et al., 2016; Bean et al., 2016). However, no study has addressed their moderating role vis-à-vis what motives lead gamers to purchase, which may prove essential for marketers in this industry. Judge et al. (2007) find that neuroticism negatively affects self-efficacy, while deGraft-Johnson et al. (2013) study the emotional stability of video gamers. In gaming user behavior, Chen et al. (2016) argue that social influence, which explains how other people's attitudes or opinions may affect an individual's decision-making, is a determining factor in social games. Lin (2010) finds a significant relationship between agreeableness and brand loyalty in the case of video games. Raja and Malik (2014) recommend exploring the moderating role of personality characteristics since they seem to play a vital role in consumer decision-making. In the same line, Markey and Markey (2010) suggest that personality must be considered an important moderating variable when analyzing video gamer behavior. They also affirm that scholars should consider the importance of studying personality as the combination of Big-five traits, since analyzing (a) certain trait/s without considering the others might lead to 
incorrect conclusions. We thus propose a second research question: $R Q_{2}$. Does personality moderate the relationship between gamer motivations and purchase intention behavior?

\section{Methodology}

\subsection{Field of study, sampling and measurement scales}

The global video game market took in 119 billion euros last year (Newzoo, 2018). In Europe, the Spanish market ranks fourth in terms of game industry revenue, after Germany, the United Kingdom, and France. Spain has more than 450 video game companies (DEV 2018). In this context, video games are the entertainment industry of the future, with revenues that outstrip the music and movie industries (DEV, 2018). From entertainment to business, the Spanish gaming industry poses fresh challenges for marketing managers and scholars to segment and understand this vast market of over 24 million gamers in Spain alone (DEV, 2018).

Following our goal of exploring whether gamers' motivations might help managers and scholars to explain purchase behavior and whether personality creates different segments of gamers, information was gathered through a questionnaire. To collect data, we used a semi-probabilistic sampling method and we contacted a group of gamers. Each was asked to answer a questionnaire and to collect two additional questionnaires from other gamers they knew. Following this non-probabilistic sampling process, a total sample of 511 valid questionnaires was collected. Participants' ages ranged from 18 to 65 years old ( $\mathrm{M}=23.4$, $\mathrm{SD}=7.4$ ) and they devoted an average of 5.7 hours per week to playing games. The sample shows some similarities to the average Spanish video game player. Taking into account the last free published ISFE data (2017), most are under 24 years old (69\%) and play an average of 5.4 hours per week.

This section briefly describes how the survey instrument was developed. Most items are coded on a five-point Likert scale ranging from Strongly Disagree (1) to Strongly Agree (5). Scales were adapted from previous literature so as to ensure the content validity of the measures (Salzberger et al., 2016). Specifically, hedonic and social motivations were 
measured by building ad hoc scales following Wei and Lu (2014) and Huang and Hsieh (2011), regarding the video game most played by each video gamer. Addiction to games was measured by using the scale proposed by van Rooij et al. (2012) and gamers' intent to purchase video game-related products was measured by employing the scale proposed by Badrinarayanan et al. (2015). As for personality traits (i.e., conscientiousness, neuroticism, extraversion, openness, and agreeableness), we adapted the Big Five scale (McCrae et al., 1986 and deGraft-Johnson et al., 2013). In line with previous literature, we included additional questions about gamers' characteristics, type of game and the device used as well as mode of gaming (Culig and Rukavina, 2012; Manero et al., 2016; DEV, 2018).

\subsection{Scale validity and testing of proposed hypotheses}

Data analysis was conducted using IBM SPSS 19 and LISREL 8.7. First, a preliminary univariant and bivariant analysis of observable variables was performed, which did not reveal significant abnormalities in the data. Variables were then studied to test their unidimensionality. In order to evaluate the structure, exploratory factor analysis (EFA) with varimax rotation revealed that the nine constructs used had eigenvalues $>1.00$ and explained $57.1 \%$ of total variance. The overall Kaiser-Meyer-Oklin (KMO) measure was .828 (Kaiser, 1974) and Bartlett's Test of Sphericity was statistically significant (p < .000), indicating that data were likely factorizable (Manero et al., 2016). Confirmatory factor analysis (CFA) determined the convergent and discriminant validity of the measurement instrument ${ }^{\mathrm{i}}$. In CFA, some items were suppressed since they failed to show the required standards to be considered reliable and valid following the recommendation of Bagozzi and Yi (2012). The reliability of the final scales was adequate according to the values recommended by Bagozzi and Yi (2012) ${ }^{[2]}$ (see Table 2). The measurement model also showed an acceptable fit: $\chi 2=1206.37(\mathrm{p}=.00)$; GFI $=.90 ;$ IFI $=.90 ;$ CFI $=$ $.90 ; \mathrm{NFI}=.90 ;$ RMSEA $=.053^{[3]}$. As regards the discriminant validity of the latent variables, results showed that the root of the variance extracted in all cases is greater than the correlations between constructs.

In order to analyze the hypothesized relationships, we then used SEM based on the maximum likelihood estimator. Table 2 shows that the model fit was adequate, and all 
hypotheses were accepted. After confirming all the proposed relationships, we conducted a cluster analysis in order to segment gamers depending on their personality and to then test the moderating effect of personality.

Table 2. Results of the SEM estimation

\begin{tabular}{lcc}
\hline Hypothesis: Relationship & $\boldsymbol{\beta}$ coefficient & Result \\
\hline H1: Hedonic motivation $\rightarrow$ Purchase intention & $.167^{* * *}$ & Accepted \\
H2: Social motivation $\rightarrow$ Purchase intention & $.111^{* *}$ & Accepted \\
H3: Addiction motivation $\rightarrow$ Purchase intention & $.621^{* * *}$ & Accepted \\
\hline Goodness of fit $\quad \chi^{2=200.03(p=0.00) ; \mathrm{GFI}=.95 ; \mathrm{IFI}=.98 ; \mathrm{CFI}=.98 ; \mathrm{NFI}=.97 ;}$ RMSEA $=.058$ \\
\hline Notation: $* * * \mathrm{p}<.001 ; * * \mathrm{p}<.05$
\end{tabular}

\subsection{Clustering and moderation analysis}

As other authors have done (Tseng, 2011; Hou, 2012; Manero et al., 2016; Fu et al., 2017) for video gamers, we ran a K-means clustering algorithm to classify gamers into different groups depending on their personality. We used the five factorial scores formerly validated as input variables. As a linkage criterion, we used the within-groups method and, to determine the distance between cases, we selected squared Euclidean distance. As input, the K-means clustering algorithm requires entering the desired number of output clusters. To find the optimal number of K clusters, we followed the standard practice of generating all possible classifications, ranging from $\mathrm{K}=\mathrm{N}$ (a cluster for each of the $\mathrm{N}$ samples) to 1 (a single cluster for all samples). We then applied the turning point location criterion recommended by Krzanowski and Lai (1988) and Manero et al. (2016). Using this accepted criterion, the number of clusters is in the range from $K=3$ to 6 . For each $K$ from 3 to 6 , we examined each clustering based on its consistency and explanatory power. The number of clusters that offer better results was $K=3$, attending to the size of the groups, the degree of significance of each factor and the position of the final center's values (FCV). The analysis of variance (ANOVA) supports the notion that the Big Five dimensions are significant at a level of $95 \%$ to characterize the groups. The values of the F statistic indicate that consciousness and neuroticism produce the largest and smallest variations between groups, respectively. Table 3 shows ANOVA analysis results and the three conglomerates information.

Table 3. ANOVA results and conglomerates information

F FCV $\quad$ Distance from conglomerate centers




\begin{tabular}{|c|c|c|c|c|c|c|c|c|c|}
\hline Factor & & $\begin{array}{c}\text { Sig. } \\
(95 \%)\end{array}$ & Analysts & Socializers & Sentinels & & $\begin{array}{c}\text { Analysts } \\
(\mathrm{n}=167)\end{array}$ & $\begin{array}{c}\text { Socializers } \\
(\mathrm{n}=202)\end{array}$ & $\begin{array}{c}\text { Sentinels } \\
(\mathrm{n}=142)\end{array}$ \\
\hline Conscientiousness & 252.361 & .000 & .78195 & .00245 & -.89892 & Analysts & & 1.730 & 1.806 \\
\hline Neuroticism & 17.451 & .000 & .29591 & -.23944 & .05483 & & & & \\
\hline Extraversion & 115.954 & .000 & -.40637 & .56953 & -.30606 & Socializers & 1.730 & & 2.053 \\
\hline Openness & 122.259 & .000 & -.30185 & .61631 & -.53127 & & & & \\
\hline Agreeableness & 112.287 & .000 & -.06201 & .48838 & -.62253 & Sentinels & 1.806 & 2.053 & \\
\hline
\end{tabular}

Notation: Final Center Value (FCV).

Gamers included in the first cluster show higher positive scores in conscientiousness $(\mathrm{FCV}=.78195)$ and neuroticism $(\mathrm{FCV}=.29591)$ and a lower negative score in extraversion (FCV $=-.40637)$ than the other groups. These individuals' personality reveals that gamers in this cluster tend to be organized, reliable, stressed, introverted and hardworking. This description could fit in with an analyst ${ }^{[4]}$ type gamer and represents $32.7 \%$ of the total sample. The second cluster includes people who show higher positive scores in extraversion $(\mathrm{FCV}=.56953)$ and openness $(\mathrm{FCV}=.61631)$ and the lowest negative score in neuroticism $(\mathrm{FCV}=-.23944)$ and agreeableness $(\mathrm{FCV}=.48858)$. This description corresponds to a type of gamer that may be termed a socializer. Socializers tend to be fun-loving, optimistic, extrovert, outgoing, curious, creative and imaginative. They also display a tendency to be self-assured and calm. This group represents $39.5 \%$ of the total sample. Finally, the third cluster display lower negative scores in consciousness (FCV=.89892), openness (FCV=-.53127) and agreeableness (FCV=-.62253). This description could fit in with sentinels. These gamers' traits reveal that sentinels tend to be conventional, unadventurous and ruthless as well as careless or disorganized. This group represents the smallest (27.8\% of the total sample).

Information from the final center values for each of the three clusters concerning the Big Five Model factors (Table 3) helps us to describe differences between clusters and to characterize them taking into account gamers' personality ${ }^{\mathrm{ii}}$.

After a descriptive analysis of the clusters, the next step is to test the moderating effect of personality in the proposed model (see Figure 1). The sample was divided into three segments of gamers [Analysts (Group 1 ); Socializers (Group 2$)$; Sentinels (Group 3 )]. We first tested metric invariance by imposing equality constraints on factor loadings across groups. The chi-square difference tests between the constrained model and the unconstrained model (base) for each group were not statistically significant [diff. $\chi^{2}$ (constrained Group1): $1.63, \mathrm{p}>.05$; diff. $\chi^{2}$ (constrained Group2): .15, $\mathrm{p}>0.05$; diff. $\chi^{2}$ (constrained Group3): 
$1.8, \mathrm{p}>.05]$. Hence, metric invariance is retained, and the base model fit is adequate $(\chi 2$ $=486.83, \mathrm{p}=.00) ; \mathrm{RMSEA}=.06, \mathrm{NFI}=.88, \mathrm{CFI}=.93, \mathrm{IFI}=.93, \mathrm{RFI}=.86, \mathrm{GFI}=.87)$. Multi-group analysis was then performed (Table 4). In this case, a model that imposed equality constraint parameters across the subgroups was compared with a non-restricted model. As regards the moderating effect of personality, the restricted model showed a significant chi-square difference $(\chi 2)$ value of $33.3(\neq \mathrm{df}=14, \mathrm{p}<.05)$.

Table 4. Multigroup analysis (moderating role of personality)

\begin{tabular}{|c|c|c|c|}
\hline \multirow{2}{*}{ Dependent variable: } & \multicolumn{3}{|c|}{ Independent variable: Purchase intention } \\
\hline & Group1. Analysts & Group2. Socializers & Group3. Sentinels \\
\hline Hedonic motivation & $\beta: .160$ (t-value: 1.98$)^{* *}$ & $\beta: .035$ (t-value: .413) & $\beta: .171$ (t-value: 1.70$)$ \\
\hline Social motivation & $\beta: .591\left(t-v a l u e:\right.$ 5.67) ${ }^{* * * *}$ & $\beta: .482$ (t-value: 4.87$)^{* * * *}$ & $\beta: .449(t-v a l u e: ~ 3.98)^{* * * *}$ \\
\hline Addiction motivation & $\beta: .073$ (t-value: .855) & $\beta:-.019$ (t-value: -.234$)$ & $\beta: .051(\mathrm{t}$-value: .545$)$ \\
\hline $\begin{array}{l}\text { Goodness of fit } \\
\text { (per group) }\end{array}$ & $\begin{array}{c}\chi^{2}=157.75 ; \text { RMR }=.07 \\
\text { GIF }=.89\end{array}$ & $\begin{array}{c}\chi^{2}=130.29 ; \mathrm{RMR}=.06 \\
\text { GIF }=.91\end{array}$ & $\begin{array}{c}\chi^{2}=121.68 ; \text { RMR }=.07 \\
\text { GIF }=.90\end{array}$ \\
\hline $\begin{array}{l}\text { Goodness of fit } \\
\text { (whole sample) }\end{array}$ & \multicolumn{3}{|c|}{$\chi^{2}=409.7(\mathrm{p}=.00) ; \mathrm{GFI}=.91 ; \mathrm{IFI}=.96 ; \mathrm{CFI}=.96 ; \mathrm{NFI}=.92 ; \mathrm{RMSEA}=.06$} \\
\hline
\end{tabular}

\section{Discussion}

The objective of this study was twofold: to ascertain the role of different types of gamer motivation to play vis-à-vis purchasing game-related products and to analyze the moderating role of gamer personality on the motivations-purchase links. Consequently, three hypotheses relating motivations and purchase intention and two research questions addressing the role of personality were proposed. The findings are particularly enlightening given that previous research has tended to describe gamers in terms of gender (Faqih, 2016; Polyzou et al., 2016) or video game genre (Culig and Rukavina, 2012; Krolo et al., 2016), and we have found only one work related to personality (Braun et al., 2016) or motivations (Tseng, 2011), but do not relate it to purchase behavior. To the best of our knowledge, no study has thus far explored the moderating effect of personality on the relationship between motivations to play and purchasing video gamerelated products.

\subsection{Academic implications}


Following the Trait Theory, this study confirms that the Big-Five factors of a gamer influence how and what game they play. Moreover, according to the Uses and Gratification Theory and the Flow Theory, gamers search for hedonic and social motivations when playing a game, and these drivers affect their purchase behavior of game-related products.

This study is innovative in that it characterizes a vast number of video gamers according to their personality and relates those gamer groups to the impact of purchase motivations. This characterization has been carried out with information gathered from a wide sample of gamers. The main contribution of this study is that, contrary to the scant number of previous studies which link general personality traits and video game types (Manero et al., 2016; Bean et al., 2016) and which offer gamers' descriptive typologies, this study provides a deeper understanding of the influence of specific motivations to play (hedonic, social and addiction drivers) on purchase intention behavior, first with the whole sample and second considering gamer personality. In line with Zimmerman (2009), in order to successfully understand, modify, and design games it is essential to find out how consumers play and think.

As a pioneering work, this study demonstrates that hedonic, social and mainly addiction factors motivate the intention to purchase game-related products. For the case of purchase behavior, these results confirm the previous research findings of Colwell (2007) and Ha et al. (2007) for entertainment products and playing intention, of Wei and Lu (2014) and Cole and Griffiths (2007) for social motives that affect gamer engagement, and of Søraker (2016) for addiction-playing intention.

Moreover, after obtaining three main groups of gamers (analysts, socializers and sentinels), this work indicates that hedonic motivation is relevant only for analysts, while social motivation proves key for the three groups. Surprisingly, when considering gamer segmentation according to their personality, addiction is not significant in any of the groups obtained. This exploratory analysis examining the role of personality is, as far as we are aware, new to the literature and would no doubt benefit from further research. 


\subsection{Managerial implications}

As Manero et al. (2016) state, when the target population of a certain game is inadequately researched before the game's design is undertaken, the outcome may be a game that fails to meet gamers' expectations and preferences. In agreement with Hou (2012), behavioral patterns help us to better understand gamers' characteristics and to develop game design in line with their preferences. Several managerial implications emerge from this research. In our opinion, scholars and marketers alike should recognize the characteristics of personality and specific motivations to play that drive video gamer preferences and behaviors. Marketers and advertisers could promote their products better (video games in our case) if they understood the psychological motivations underlying why individuals purchase certain products (Sandy et al., 2013; Mukherjee and Lau-Gesk, 2016). Moreover, firms should foster gamer enjoyment, help players to test their skills during game playing and promote interaction with others, since all these strategies help to sell game-related products. In addition, if firms can encourage gamers to spend more time playing by favoring access to games through different anywhere and anytime devices, gamers are likely to become more engaged and addicted to playing and will finally be more likely to purchase game-related products.

Apart from the general impact of motivations on purchase intention, differences can be found if personality is included in management strategies. By studying the role played by gamer personality, our work can help managers and content game designers both before they create the game (by providing information about the behavior and characteristics of potential gamers) and after the game has been created and is to be launched onto the market (by offering three well described potential personality-based gamer targets). In agreement with Konzack (2009), game design must be based on player behavior. The link between motivations and game purchase behavior can add valuable information to the obtained classification based on gamers' personality. First, analysts need hedonic stimuli if they are to be thrilled and have their skills put to the test when playing. This segment is a challenge for marketers since players like games which stimulate their logical personality. One strategy for bringing this target closer might be to develop new and entertaining gaming apps for smartphone or tablet that are more specific to a predominantly feminine segment. Second, socializers might show their particular 
extrovert and open personality by recommending and recruiting friends and relatives to game with them, as they are fond of searching for social motivations. In this case, firms may take advantage of player preference for competitive, strategy, adventure and sport games. This dominant masculine group represents the potential and priority target for competitive and combat video games. Moreover, socializers play more with consoles than the other groups do, which could mean they represent the most receptive audience for promoting community or multi-group gaming competitions, not only because of their social motivation, but also due to their personality traits, which align better with the socializing process. Finally, the smallest of the three groups to emerge, sentinels, is a difficult target to attend to a priori as they are not open or emotionally stable. This segment may be a priority segment for firms' promotional and marketing communication activities through computers and popular games guided mainly by social motivation. Firms should address reference groups of gamers so as to encourage sentinels to buy.

\subsection{Limitations and further research}

Results are confined to Spain, in addition to which this study is limited to the video game industry. Furthermore, we use a short version of the Big Five inventory. Future studies should consider using another measurement instrument such as the 60-item NEO fivefactor inventory (Costa and McRae, 1992). It would also be wise to compare real-world and virtual-world activities so as to know whether adopting certain activities such as game app playing is a substitute for their real-world counterpart, a research line advocated by Eastin (2002). Finally, we must recognize there are other important motives for playing video games (beyond those examined here), such as acquiring knowledge (learning), or sharpening gamers' skills and capacities. Future research should thus investigate further and include other determinants of purchase intention of related video game products. In this sense, the development of information and Internet technologies has led to a drastic transformation of both business processes as well as the video game industry itself, and in future more app games are expected to be used rather than consoles or computers, which might satisfy gamer motivations differently. Finally, further research is necessary on addiction motivation. In particular, the search for an alternative operationalization of its measurement might reveal more insightful evidence concerning the effect of this 
variable on gamer behavior. This is only a preliminary study and exploring different future lines of research is no doubt necessary.

\section{References}

Abarbanel, B.L. (2013), "Mapping the online gambling e-servicescape: A conceptual model”, UNLV Gaming Research \& Review Journal, Vol. 17, No. 2, pp. 27-44.

Badrinarayanan, V. A., Sierra, J. J., and Martin, K. M. (2015), “A dual identification framework of online multiplayer video games: The case of massively multiplayer online role playing games (MMORPGs)", Journal of Business Research, Vol. 68, No. 5, pp. 1045-1052.

Bagozzi, R.P., and Yi, Y. (2012), "Specification, evaluation, and interpretation of structural equation models", Journal of The Academy of Marketing Science, Vol. 40, No. 1, pp. 8-34.

Bateman, C. and Boon, R. (2005). 21st Century Game Design. Boston: Charles River.

Bean, A. M., Ferro, L. S., Vissoci, J. R. N., Rivero, T., and Groth-Marnat, G. (2016), "The emerging adolescent World of Warcraft video gamer: A five factor exploratory profile model”, Entertainment Computing, Vol. 17, No. 11, pp. 45-54.

Berridge, K. (2007), “The debate over dopamine's role in reward: the case for incentive salience", Psychopharmacology, Vol. 191 No. 3, pp. 391-431.

Boyle, E. A., Connolly, T. M., Hainey, T. and Boyle, J. M. (2012), "Engagement in digital entertainment games: A systematic review", Computers in Human Behavior, Vol. 28, No. 3, pp. 771-780.

Braun, B., Stopfer, J. M., Müller, K. W., Beutel, M. E. and Egloff, B. (2016), "Personality and video gaming: Comparing regular gamers, non-gamers, and gaming addicts and differentiating between game genres", Computers in Human Behavior, Vol. 55, pp. 406412.

Chen, A.; Lu, Y. and Wang, B. (2016), "Enhancing perceived enjoyment in social games through social and gaming factors", Information Technology \& People, Vol. 29, No. 1, pp. 99-119. 
Chen, C. and Leung, L. (2016), "Are you addicted to Candy Crush Saga? An exploratory study linking psychological factors to mobile social game addiction", Telematics and Informatics, Vol. 33, No. 4, pp. 1155-1166.

Chen, Z.G. and Chang, Y.X. (1989), "Psychology of Personality”, Wu-Nan Book Inc., Taipei.

Csikszentmihalyi, M. (1975), Beyond Boredom and Anxiety, San Francisco, CA: Jossey Bass.

Cole, H. and Griffiths, M.D. (2007), "Social interactions in massively multiplayer online roleplaying gamers", CyberPsychology \& Behavior, Vol. 10 No. 4, pp. 575-583

Colwell, J. (2007), "Needs met through computer game play among adolescents", Personality and Individual Differences, Vol. 43, No. 8, pp. 2072-2082.

Costa, P.T. and McCrae, R.R. (1985), The NEO Personality Inventory manual, Florida: Odessa, Psychological Assessment Resources.

Costa, P.T.Jr. and McRae, R.R. (1992), Revised NEO Personality Inventory (NEO-PI-R) and NEO Five-Factor Inventory (NEO-FFI) professional manual, Florida: Odessa, Psychological Assessment Resources, Inc.

Cronbach, Lee J., and Richard J. Shavelson (2004), "My current thoughts on coefficient alpha and successor procedures," Educational and Psychological Measurement, Vol. 64, No. 3, 391-418.

Culig, B. and Rukavina, I. (2012), "Psychology and sociocultural determinants of typology of video gamers, in Cultural perspectives of video games: from designer to gamer”. Oxford, UK: Inter-Disciplinary Press, 2012., available in April 2017 in http://www.inter-disciplinary.net/critical-issues/wpcontent/uploads/2012/07/VG4_websitepaper_Culig_Rukavina.pdf

Davis, R., Lang, B., and Gautam, N. (2013), "Modeling utilitarian-hedonic dual mediation (UHDM) in the purchase and use of games", Internet Research, Vol. 23, No. 2, 229-256.

deGraft-Johnson C., Yu-Chi, W., Bradlee, M. and Norman, K.L. (2013), "Relating Five Factor Personality Traitsto Video Game Preference; Human-Computer Interaction Technical Report”, retrieved in October 2017 from http://hcil2.cs.umd.edu/trs/201308/2013-08.pdf 
DEV-Spanish Association of Enterprises Producers and Developers of Video Games and Entertainment Software (2017), "Libro blanco del desarrollo español de videojuegos", retrieved in June 2018 from www.dev.org.es

Drachen, A., Canossa, A. and Yannakakis, G. N. (2009), "Player modeling using selforganization in Tomb Raider: Underworld”, In Computational Intelligence and Games, IEEE Symposium, pp. 1-8.

Drachen, A., Sifa, R., Bauckhage, C. and Thurau, C. (2012), "Guns, swords and data: Clustering of player behavior in computer games in the wild", In Computational Intelligence and Games IEEE Conference, pp. 163-170.

Eastin, M. S. (2002), "Diffusion of e-commerce: an analysis of the adoption of four ecommerce activities", Telematics and informatics, Vol. 19, No. 3, pp. 251-267.

Estallo, J. A. (1995), Los videojuegos: Juicios y prejuicios: Guía para padres. Planeta: Madrid.

Faqih, K.M.S. (2016), "An empirical analysis of factors predicting the behavioral intention to adopt Internet shopping technology among non-shoppers in a developing country context: Does gender matter?", Journal of Retailing \& Consumer Services, Vol. 30, No. May, pp. 140-164.

Festinger, L. (1954), “A theory of social comparison processes”, Human relations, Vol. 7, No. 2, pp. 117-140.

Fu, X., Chen, X., Shi, Y. T., Bose, I. and Cai, S. (2017), "User Segmentation for Retention Management in Online Social Games”, Decision Support Systems, Vol. 101, pp. 51-68.

George, D., and Mallery, P. (2003). SPSS for Windows step by step: A simple guide and reference. 11.0 update (4th ed.). Boston: Allyn \& Bacon.

Griffiths, M. D., Davies, M. N. and Chappell, D. (2004), "Online computer gaming: a comparison of adolescent and adult gamers" Journal of adolescence, Vol. 27, No. 1, pp. $87-96$.

Ha, I., Yoon, Y. and Choi, M. (2007), "Determinants of adoption of mobile games under mobile broadband wireless access environment", Information \& Management, Vol. 44 No. 3, pp. 276-286. 
Hartmann, T. and Klimmt, C. (2006), “Gender and computer games: Exploring females' dislikes", Journal of Computer - Mediated Communication, Vol. 11, No. 4, pp. 910-931.

Hou, H. T. (2012), "Exploring the behavioral patterns of learners in an educational massively multiple online role-playing game (MMORPG)", Computers \& Education, Vol. 58, No. 4, pp. 1225-1233.

Huang, L. Y. and Hsieh, Y. J. (2011), "Predicting online game loyalty based on need gratification and experiential motives", Internet Research, Vol. 21, No. 5, pp. 581-598.

Huang, T., Huang, T., Bao, Z., Bao, Z., Li, Y. and Li, Y. (2017), "Why do players purchase in mobile social network games? An examination of customer engagement and of uses and gratifications theory", Program, Vol. 51, No. 3, pp. 259-277.

Ip, B., Jacobs, G. and Watkins, A. (2008), "Gaming frequency and academic performance" Australasian Journal of Educational Technology, Vol. 24, No. 4, pp. 355373.

ISFE (2017), “GameTrack Digest: Quarter 1”, retrieved in March 2018 from https://www.isfe.eu/sites/isfe.eu/files/gametrack_european_summary_data_2017_ q1.pdf

Jeromin, F., Rief, W., and Barke, A. (2016), "Validation of the Internet Gaming Disorder Questionnaire in a Sample of Adult German-Speaking Internet Gamers", Cyberpsychology, Behavior, and Social Networking, Vol. 19, No. 7, pp. 453-459.

Judge, T.A., Jackson, C.L., Shaw, J.C., Scott, B.A., and Rich, B.L (2007), "Self-efficacy and Work-Related Performance: The Intregral Role of Individual Differences", Journal of Applied Psychology, Vol. 92, No. 1, pp. 107-127.

Kaiser, H. F. (1974), “An index of factorial simplicity”, Psychometrika, Vol. 39, No. 1, pp. 31-36.

Krolo, K.; Zdravkovic and Puzek, I. (2016), "Typology of Video Gamers in Croatia: Some Socio-Cultural Characteristics”, Media Studies, Vol. 7, No. 13, pp. 25-41.

Krzanowski, W. J. and Lai, Y. T. (1988), "A criterion for determining the number of groups in a data set using sum-of-squares clustering”, Biometrics, Vol. 44, No. 1, pp. 23 34. 
Konzack, L. (2009). Philosophical Game Design. In: Perron \& Wolf (eds.) The Video Game Theory Reader 2 . New York \& London: Routledge, p. 33-44

Kuo, A., Lutz R.J. and Hiler J.L. (2016), "Brave new World of Warcraft: a conceptual framework for active escapism”, Journal of Consumer Marketing, Vol. 33, No. 7, pp. 498-506.

Landers, R.N. and Lounsbury, J.W. (2006), “An investigation of Big Five and narrow personality traits in relation to Internet usage", Computers in Human Behavior, Vol. 22, No. 2, pp. 283-293.

Li, H., Liu, Y., Xu, X., Heikkilä, J. and Van Der Heijden, H. (2015), "Modeling hedonic is continuance through the uses and gratifications theory: An empirical study in online games", Computers in Human Behavior, Vol. 48, pp. 261-272.

Liu, C. (2017) "A model for exploring gamers flow experience in online games", Information Technology \& People, Vol. 30, No. 1, pp.139-162

Liu, C. C., and Chang, I. C. (2016), "Model of online game addiction: The role of computer-mediated communication motives", Telematics and Informatics, Vol. 33, No. 4, pp. 904-915.

Lin, L-Y. (2010), "The relationship of consumer personality trait, brand personality and brand loyalty: an empirical study of toys and video games buyers", Journal of Product \& Brand Management, Vol. 19, No. 1, pp. 4-17.

Love, P. E. and Irani, Z. (2007), "Coping and psychological adjustment among information technology personnel”, Industrial Management \& Data Systems, Vol. 107, No. 6, pp. 824-844.

Loveland, J. M., Lounsbury, J. W., Park, S. H., and Jackson, D. W. (2015), “Are salespeople born or made? Biology, personality, and the career satisfaction of salespeople", Journal of Business \& Industrial Marketing, Vol. 30, No. 2, pp. 233-240.

Lu, H. P., and Wang, S. M. (2008). The role of Internet addiction in online game loyalty: an exploratory study, Internet Research, Vol. 18, No. 5, pp. 499-519.

Manero, B., Torrente, J., Freire, M., and Fernández-Manjón, B. (2016), “An instrument to build a gamer clustering framework according to gaming preferences and habits", Computers in Human Behavior, Vol. 62, No. September, pp. 353-363. 
Markey, P. M., and Markey, C. N. (2010). Vulnerability to violent video games: a review and integration of personality research, Review of General Psychology, Vol. 14 No. 2, pp. $82-91$.

McBride, J., and Derevensky, J. (2009). Internet gambling behavior in a sample of online gamblers, International Journal of Mental Health and Addiction, Vol. 7, No. 1, pp. 149167.

McCrae, R. R., Costa, P. T., Jr., and Busch, C. M. (1986), "Evaluating comprehensiveness in personality systems: The California Q-Set and the five-factor model", Journal of Personality, Vol. 54, No. 2, pp. 430-446.

Mehrabian, A. and Russell, J.A. (1974), "An approach to environmental psychology". Cambridge: MIT Press.

Mogre, R., Lindgreen, A., and Hingley, M. (2017), "Tracing the evolution of purchasing research: future trends and directions for purchasing practices”, Journal of Business \& Industrial Marketing, Vol. 32, No. 2, pp. 251-257.

Mount, M. K., Barrick, M. R., Scullen, S. M., and Rounds, J. (2005), "Higher-order dimensions of the big five personality traits and the big six vocational interest types", Personnel Psychology, Vol. 58, No. 2, pp. 447-478.

Mukherjee, S. and Lau-Gesk, L. (2016), "Retrospective evaluations of playful experiences", Journal of Consumer Marketing, Vol. 33, No 5, 387-395.

Newzoo (2018), “2018 Global Games Market Report”, retrieved in June 2018 from https://newzoo.com/key-numbers/

Peterson, R. A., and Kim, Y. (2013), “On the relationship between coefficient alpha and composite reliability", Journal of Applied Psychology, Vol. 98, No. 1, 194.

Polyzou, E.; Hasanagas, N., and Tamoutseli, K. (2016), “A Gender-based Typology of Determinants of Video Games Use by Primary School Children, in proceedings of Digital Landscape Architecture" in 2nd International CEMEPE \& SECOTOX Conference, Mykonos, Greece, 141-156, retrieved in October 2017 at http://www.kolleg.loel.hsanhalt.de/landschaftsinformatik/fileadmin/user_upload/_temp_/2012/Proceedings/Buhm ann_2012_15_Polyzou_at_al.pdf 
Raja, J. I., and Malik, J. A. (2014), "Personality Dimensions and Decision Making: Exploring Consumers' Shopping Styles”, Journal of Behavioural Sciences, Vol. 24, No. 2, pp. 18-33.

Roberts, B. W., Kuncel, N. R., Shiner, R., Caspi, A. and Goldberg, L. R. (2007), “The power of personality: The comparative validity of personality traits, socioeconomic status, and cognitive ability for predicting important life outcomes", Perspectives on Psychological Science, Vol. 2, No. 4, pp. 313-345.

Ryan, R. and Deci, E. (2000), "Self-determination theory and the facilitation of intrinsic motivation, social development, and well-being", American Psychologist, Vol. 55 No. 1, pp. 68-78.

Ryan, T. and Xenos, S. (2011), "Who uses Facebook? An investigation into the relationship between the Big Five, shyness, narcissism, loneliness, and Facebook usage", Computers in Human Behavior, 27, 5, 1658-1664.

Saleem, H., Beaudry, A., and Croteau, A-M. (2011), “Antecedents of computer selfefficacy: A study of the role of personality traits and gender", Computers in Human Behavior, Vol. 27, No. 5, pp. 1922-1936.

Salzberger, T., Sarstedt, M., and Diamantopoulos, A. (2016), "Measurement in the social sciences: Where C-OAR-SE delivers and where it does not", European Journal of Marketing, Vol. 50, No. 11, pp. 1942-1952.

Sandy, C. J., Gosling, S.D., and Durant, J. (2013), "Predicting consumer behavior and media preferences: The comparative validity of personality traits and demographic variables", Psychology \& Marketing, Vol. 30, No. 11, pp. 937-949.

Sheu, J. J., Su, Y. H. and Chu, K. T. (2009), "Segmenting online game customers-The perspective of experiential marketing”, Expert systems with applications, Vol. 36 No. 4, pp. 8487-8495.

Søraker, J. H. (2016), "Gaming the gamer?-The ethics of exploiting psychological research in video games", Journal of information, communication and ethics in society, Vol. 14, No. 2, pp. 106-123.

Teng, C. I. (2008), "Personality differences between online game players and nonplayers in a student sample", CyberPsychology \& Behavior, Vol. 11, No. 2, pp. 232-234. 
Tseng, F. C. (2011), "Segmenting online gamers by motivation”, Expert Systems with Applications, Vol. 38, No. 6, pp. 7693-7697.

van Rooij, A. J., Schoenmakers, T. M., Van den Eijnden, R. J., Vermulst, A. A., and van de Mheen, D. (2012), "Video game addiction test: validity and psychometric characteristics", Cyberpsychology, Behavior, and Social Networking, Vol. 15, No. 9, pp. 507-511.

Velez, J. A. and Hanus, M. D. (2016), "Self-Affirmation Theory and Performance Feedback: When Scoring High Makes You Feel Low", Cyberpsychology, Behavior, and Social Networking, Vol. 19, No. 12, pp. 721-726.

Wei, P. S. and Lu, H. P. (2014), "Why do people play mobile social games? An examination of network externalities and of uses and gratifications", Internet Research, Vol. 24, No. 3, pp. 313-331.

Williams, D., Yee, N. and Caplan, S. E. (2008), "Who plays, how much, and why? Debunking the stereotypical gamer profile", Journal of Computer-Mediated Communication, Vol. 13, No. 4, pp. 993-1018.

Williams, J. P. (2016), Playing Games is (Not Always) Fun, retrieved in October 2017 from

https://www.researchgate.net/profile/J_Williams2/publication/317162680_Playing_Ga $\underline{\text { mes/links/59278952aca27295a800ebdc/Playing-Games.pdf }}$

Worth, N.C. and Book, A.S. (2014), "Personality and behavior in a massively multigamer online role-playing game", Computers in Human Behavior, Vol. 38, No. September, ,pp. 322-330.

Yee, N. (2006), “The labor of fun: How video games blur the boundaries of work and play", Games and culture, Vol. 1, No. 1, pp. 68-71.

Zammitto, V. L. (2010), “Gamers' personality and their gaming preferences”, School of Interactive Arts and Technology, University of Belgrano.

Zimmerman, E. (2009), "Gaming literacy: Game design as a model for literacy in the twenty-first century", The video game theory reader, Vol. 2, pp. 23-31.

\footnotetext{
${ }^{[1]}$ Gaming refers throughout the paper to playing with video games.

i The results of the adjusted model and correlations are available to readers upon request.
} 
[2] The values of the alpha Cronbach coefficient were $>.7$ (except for five of them, which were slightly lower), the coefficient of composite reliability >.6 and the average variance extracted >.5. Although the Cronbach alpha is the most widely used estimator of scale reliability, it is felt to underestimate reliability. A better option to test reliability is composite reliability (Peterson and Kim, 2013), which might be affected by the small number of items (George and Mallery, 2003; Cronbach and Shavelson, 2004).

${ }^{[3]} \chi 2$ : chi-square statistic, RMSEA: Root-Mean-Square-Error of Approximation, NFI: Normed Fit Index, RMR: Root Mean-Squared Residual and GFI: Goodness-of-Fit Index, CFI: Comparative Fit Index.

${ }^{[4]}$ The chosen names of the groups aim to reflect an analogy with gamers' roles and/or avatars so as to make it easier for firms working in the video game industry to identify consumer types.

ii Further details on cluster characterization analysis may be requested from the authors. 